\title{
Should Public Administration Be Internationalized
}

\author{
Tam T.H Mai \\ Florida Atlantic University, Florida, USA
}

\begin{abstract}
This study aims to explain why internationalizing American public administration program is necessary. The internationalization of public administration program means that American public administration programs not only include American students, but also foreign students who come from different countries in the world who still need to meet the common requirements of admission. The challenges and opportunities faced in internationalizing American public administration are outlined in this study. Realism theory explains opportunities created by the internationalization of American public administration and also presents challenges of internationalizing American public administration. Applying the methodology of library research, this study affirms that despite the challenges, internationalization of public administration is necessary to integrate thinking, enhance cognitive flexibility, and meet the increasing and diverse demands of globalization. The study insists that better service for these new foreign students creates mutual benefits, not only for the foreign students but also for American public administration. The internationalization of public administration is a strategy that should be adopted by public administration field of every country in the world.
\end{abstract}

Keywords: internationalization, public administration, realism, opportunities and challenges

Internationalization of educational programs has become one of the main strategies in recent years. Internationalization of higher education in general (Altbach \& Teichler, 2001) and of public administration programs in particular occurs in conjunction with the inevitable trend of globalization. The internationalization of public administration meets the demand of "the global academic marketplace for both students and staff" (Altbach \& Teichler, 2001, p. 6). The markets of scholars and researchers become global, in which the US and Western countries do not hesitate to hire foreign talented students, scholars, and researchers. After graduating from public administration program, each foreign student may have different goals. Some may settle down and find a job in the US, while others may use their knowledge and experiences in the US to address their own needs in their contexts in their home country. The influences and impacts of American public administration on these students' careers are significant for working in their home country or settling down in the US.

Undoubtedly, public service has been broadened from governmental level to intergovernmental levels, from a national to a global scope (Kettl, 2000). Public administration needs to change to adapt with the new context of globalization. Internationalization strategy of public administration makes an important contribution to improving the bureaucratic system in "customer-driven and service-oriented" direction (Barzelay, 1992, as cited in Shafritz, 2004, p. 534). The internationalization of public administration will transform public administration from an authoritarian position to better serving different citizen groups.

Corresponding author: Tam T.H Mai, Ph.D., School of Public Administration, Florida Atlantic University, USA; research fields: public administration, international relations, human rights, critical theory, branding, human trafficking, and empowering women. 
The internationalization of public administration creates numerous opportunities for foreign students to acquire knowledge when they study in the US. When they come back to their home country, they can apply their learned knowledge and make contributions to national development. Additionally, these foreign students play important roles in enhancing the relations between the US and their home country in education in general, and public administration in particular. The American public administration is approached from different perspectives and views by foreign students who come from various cultures and contexts, which increases diversity and enrichment for American public administration.

\section{Theoretical Framework}

The strategy of internationalizing public administration is rooted in realism theory. Realism is the opposite of idealism and is based on "a fact or (...) an event without idea, without generalization" (Vereshchagin, 1889, p. 5). After Cold War, the internationalization is "inescapably tough to handle" (Newland, 1997, p. II), which is the unavoidable trend that public administration cannot ignore. According to realism theory, the basis of public administration is constitutional democracy, which forms the central idea behind the internationalizing of public administration.

Realists assume that states are the most important players in the international arena. Non-state actors only hold a secondarily important position. "States are unitary and rational" (Viotti \& Kauppi, 1987, p. 35; Brooks $\&$ Wohlforth, 2005). States decide to internationalize public administration because they believe that their decisions are rational. States' decision to internationalize public administration is based on calculation of their interests, in which states speculate that internationalization of public administration brings more benefits for them (Viotti \& Kauppi, 1987).

According to realists, the external rather than domestic environment will control the behavior of states. Within the context of globalization, many issues such as climate change, migration, terrorism, and financial instability are transnational problems. They are becoming trans-boundaries that cannot be solved at a unilateral and bilateral level but at a global level. Internationalization of public administration can be approached with moral realism (Carr, 1964) because states can learn from each other, increase cooperation, and help each other to deal with issues that one state alone cannot solve. The internationalization of public administration contributes to dealing with global issues.

States consider their action rationally, which means that states set up various goals and objectives and they will make different choices to maximize utility. States acknowledge the shortcomings of rational actions, for example: lack of information, subjectivity, misleading information. However, they still believe their actions are consistent and expect the high value trade-offs of their action, in other words, being rational. The strategy of internationalizing public administration is considered to be rational by state actors.

Cooperation among states is necessary. In order to achieve success, states sometimes cannot work alone but need the cooperation of other states. However, interdependence does not mean that states are too dependent. In the international system, the interdependence of states indicates that there is a connection among states that contact and communicate to discuss and exchange information from one to another (Keohane, 1984). Realists believe that conflicts are inevitable in international relations. To deal with conflicts and "to establish peace is to eliminate or minimize contact among opponents or potential adversaries" (Viotti \& Kauppi, 1987, p. 57). Cooperation helps to reduce conflicts in international relations. 
How can states still play with one another and cooperate and act rationally to achieve value-maximum interests in the environment of distrust and doubt? Game theory helps to explain this question. For example, Prisoner's Dilemma (Poundstone, 1992) is the cooperative defect in which states will not cooperate even they can achieve the best interests (If you know what I know, you know I know it. I know you know). The theory stag hunt of Rousseau explains in international relations that states always observe the actions of others because states assume that other states act only to serve the interests of themselves. However, states also believe that cooperation is important to achieve higher interests. In order to achieve greater interests (catching a stag), states must cooperate with one another. Otherwise, one will catch a hare, and the other will not be able to catch a stag without the assistance of the others, which is less beneficial than if they cooperate with one another. Thus, internationalization of public administration contributes to the enhancement of cooperation among state and non-state actors.

\section{Methodology}

Library research is the methodology of this study. Sources of information based on key words from both internet and virtual references are databases on the topic of internationalizing public administration. The database basics are divided into three types: author, title, and subject. Internationalization and public administration are key terms. Nevertheless, other similar words of internationalization such as: "globalization", "deterritoralization", and "inter-nationalization" are focused. To broaden the research, the preliminary reading of reference books and journal articles is conducted. The evaluation of the sources is reliant on a variety of criteria, for example: year of publication, the reputation of publisher, title of journal, and books. The abstract, writing style, and the review are paid attention to achieving overall understanding of the content. A clear distinguishment is made between scholarly periodicals and non-scholarly periodicals. For the internet resources, advanced research is used to achieve more information on the sources. The references of the selected books and journal articles are also examined to provide more literature for the topic of internationalizing public administration programs.

\section{Analysis}

Internationalization of public administration is beneficial for both the US and home country of foreign students. For example, the internationalization of public administration can be a tactic to increase the influence of the United States not only in international relations, but also in public administration (Viotti \& Kauppi, 1993), to increase the position of the US in the world. In return, the states that have students pursuing public administration in the US can learn from the US and apply knowledge in their home country. If they settle down in the US, with the knowledge they achieve, they can make contribution to the national development of the US.

Globalization is closely linked with neoliberalism (market liberalizations) and individualism, in which state regulations and protection tariffs are removed and replaced with the free trade of markets (Steger, 2002). Public administration works for states, and when state regulations and protection tariffs are taken away, public administration territories are narrowed or "shrunk" (Farazmand, 1999). The role of government has decreased in the context of globalization (Farazmand, 1999). Thus, the internationalization of public administration is expected to increase the strength of public administration in particular and of states in general in the competitive field with non-state actors, especially corporations. One important part of realism is the approach of pragmatism, which means that when states are under threat, they make themselves stronger or find friends 
(Brooks \& Wohlforth, 2005). Public administration is faced with the threat of shrinking territories in the context of increasing privatization (Farazmand, 1999). The internationalization strategy of public administration is pragmatic to help states to ensure survival and promote security (Machiavelli, 2003). The shrinking of public administration territories happens not only in the US but in every country in the world. The internationalization of public administration will increase cooperation among states and cope with this shrinking threat.

The strategy of internationalization is congruent with the important ideas of representative bureaucracy. The theory is to build a bureaucracy as an institution which develops in democratic contexts and is non-discriminatory to anyone, neither black nor white people (Kingsley, 1944). Bureaucracies should serve as a bridge of different agencies which compete with one another to achieve the highest interests (Waldo, 1948). The complex and uneasy relationship between democracy and bureaucracy should be acknowledged, and the coexistence of democracy and bureaucracy is of great significance. The reconciliation between bureaucracy and democracy will help to build a "good society" (without poverty, corruption, and widening gap between the rich and the poor) (Waldo, 1948), in which the knowledge, capability, morality, and accountability of bureaucrats are important. The internationalization of public administration aims to promote a "good society" (Waldo, 1948).

\section{Opportunities of Internationalizing Public Administration}

Internationalization of public administration is along the same lines as the strategy of internationalizing colleges of the US (Vest, Boyer, \& Moses, 2014). To maintain the strategy of being a leading nation, the US must take the lead in the field of education (Vest et al., 2014). According to former Duke University president, Nannerl Keohane,

If we as a nation are going to become better prepared to deal with an increasingly interdependent world, then the front line has to be in our colleges and universities where we prepare students to become leaders in global enterprises, to serve in the Foreign Service, to be leaders of their communities who are sensitive to international issues. (NAFSA, 2004, p. 29)

Internationalizing public administration is one part of internationalizing colleges of the US. Foreign students who pursue public administration in the US are expected to be in the "front line" of global public administration, which is significant for both the US and their home country.

The world is "smaller" and more open due to the development of information technology. Information technology becomes more developed, which narrows the boundaries, facilitates cooperation, and produces high-speed mobility. Thus, the internationalization of public administration can be achieved more easily within this trend. The world continues to be faced with challenges of the blooming of population, environmental issues such as climate change, global warming, lack of energy and natural resources to meet the development demand, shortage of food, the increasing public debt (O’Leary \& Van Slyke, 2010). With the increase in globalization and interdependence among nations, public administration is not only surrounded around the issues of America but will be extended to global world. There are complex governance issues that not only America can deal with but need the larger international institutions and the cooperation of other countries. The traditional barrier breaks up and there will be more cooperation and integration. To deal with those changes, "a broader conceptualization of public service is needed —one that crosses boundaries" (O'Leary \& Van Slyke, 2010, p. 57), which stresses on the governance, government institutions to promote the coordination and cooperation. Public policy will cover not only input but also output. The internationalization of public administration creates more opportunities for dealing with global challenges. 
States cooperating is because they have fear. The global challenges bring "fear" for states. "Causes of fear" (Thucydides, 2006, as cited in Viotti \& Kauppi, 1987, p. 38) are the reasons why states should promote the process of internationalizing public administration and build collective strength and team spirit to cope with challenges. Public administration staff should be smarter, working as professional and skillful public servants who come from different fields and areas in the global world to work out the best solution for the problems. The issues such as: poverty, the security of food and water, and economic development will be handled by the cooperation of different leaders in the world. The internationalization of public administration creates opportunities for increasing cooperation.

\section{Challenges of Internationalizing Public Administration}

The strategy of internationalizing public administration is faced with challenges. Firstly, the internationalization of public administration is closely linked with rigid rules, regulations, and "red tape" of bureaucracy (Davies, 1998). Bureaucracy with many demands of paperwork (the files), permission, and acceptance from different agencies can be rigid and may slow down the internationalization process: visa, immigration, and the demanding requirements of paperwork that exemplifies these demands (Weber, 1947; Downs, 1967). The bureaucracy in the home country of foreign students as well as the bureaucracy in the US may slow down the internationalization process, for instance, visa, immigration, and demanding requirement of paperwork.

However, the power of bureaucracy is demonstrated through its representation for citizens (Krislov, 1974). The internationalization of public administration will increase the representation for citizens. With its demographic nature, bureaucracy can represent clients if it can help to increase the interests for clients and vice versa. If the representativeness of bureaucracy increases, people may have more interests. Representative bureaucracy is originated from the issue of struggling against inequality for black people and women in the US. Creating equal opportunities for all people is the goal that is set up in representative bureaucracy. As a diverse country with different races, ethnic identities, and genders, the representative bureaucracy is of great significance for American society. According to Krislov (1974), "The concept of representative bureaucracy was originally developed to argue for a less elite, less class-biased civil service” (Krislov, 1974, p. 354).

Moreover, internationalizing public administration is faced with difficulties. Foreign students studying in the US are not always familiar with American culture. They may experience culture shock for the first time. Helping them to be familiar and harmonize with different cultures is very important. Acculturation rather than assimilation (Farazmand, 2002) should be promoted so foreign students can feel that their own culture is still maintained and promoted, while it is immersed in American culture. If students settle down in the US, the acculturation is a strategy to enhance harmony in a diverse society like the US. Non-Western citizens will not feel that they have lower positions than Western citizens and they can be confident in trying their best to contribute to national development. Acculturation also shows that differences of culture must be respected so the internationalization of public administration can bring about the highest benefits for both foreign students and American public administration.

Another challenge of internationalizing public administration is that foreign students may have different ways of knowing (WOKs) (Van Buuren, 2009). The differences cause controversies, conflicts, and prevent the development of collective action. To deal with this issue, it is necessary to evaluate the origins of WOKs and be able to arrange those WOKs and integrate them into collaborative governance. In other words, the ability to 
organize different capacities as the result of different knowledge is important. Different knowledge can come from different facts, methods, interpretations, conditions, and perceptions. In fact, not only foreign students have WOKs, but native speakers themselves also have WOKs. However, coming from different contexts, foreign students may have different interpretations of context. Thus, there should be a strategy to arrange their capacities, so different WOKs do not prevent the cooperation, coordination, and the development of talent and capacity for both organizational and social development.

Additionally, the scale and scope of public administration issues will be broader and more complex, not only limited in one boundary, for example in only the US but across countries, from local to global level. However, the government's ability to timely cope with challenges is still limited and public administration must be changed from inactive to proactive to bring about "positive outcomes for citizens and communities" (O’Leary \& Van Slyke, 2010, p. 8), which cannot happen overnight. Affected by the various disciplines, Pollitt (2010) questioned what the destinations of public administration are. Most of scholars were not "pure scholars" (Pollit, 2010, p. 292) of public administration. They just sometimes work in public administration as advisors in both specific areas or for public authorities, or recently worked as consultants so they may not make full contribution to the field.

\section{Discussions and Conclusions}

The strategy of internationalizing public administration is rooted in realism theory. The internationalization of public administration is to "act globally and think locally" (Corbett, 2009), which is a pragmatic way to meet the increasing demands of global public administration. The internationalization of public administration is necessary to better deal with challenges such as financial crisis, increasing population, aging society, climate change, food issues, and information technology which continues to affect the scholarly field of public administration. The internationalization of public administration helps public administrators to better fulfill their responsibility and public administration's importance to be more recognized.

Internationalizing public administration does not mean that the US only accepts foreign students coming to the US to study. American students whose major is public administration should be provided opportunities to study public administration abroad and help other developing countries in public administration if it is needed. Through the exchange of foreign students, both foreign public administration and American public administration can help each other with the "shrunken" territories of public administration due to the development of private sectors and corporations (Farazmand, 2002).

Public administration is strongly advised to think and act "strategically" to increase information-sharing, cooperation, and collaboration of all governments in the world (O'Leary \& Van Slyke, 2010). The internationalization of public administration means to think and act strategically. For example, public administration is not only limited to work within the government but must be expanded outside the government and join the broader network of governance. The internationalization process helps public administration to be more practical, specifically, "relevant, and applicable, practitioner friendly, action oriented, context sensitive, done collaboratively and in an interdisciplinary fashion" (O’Leary \& Van Slyke, 2010, p. 8). Regarding teaching, renovations will be made so that both American and foreign public administration students are encouraged to be more active, more engagement into practice, are provided knowledge and skill in dealing with the new challenges of public policy. Public administration is characterized with the culture of interdisciplinary not only at local but more importantly at global level, in which theory and practice are closely linked to each 
other. Stakeholders of public administration will be more diverse, the issues of civil society and free enterprise will be focused in the area of public administration.

Public administration approach will be more practical in future and needs a governance orientation to link scholarship with the realities of practice (Gulick as cited in Meier, 2010, p. 282). The internationalization of public administration is a practical strategy, in which public administration is not only focused on administration but also governance, in which public administration will be given more power. Public administrators give advice to political field, suggest changes for political ideas, and bring about better governance. Thus, internationalizing public administration increases the position of public administration field, in which the combination of both politics and administration in governance is evident.

To make better achievements in the strategy of internationalizing public administration, there should be changes for the structures of public administration organization, in which democratic control is more protected. The top-down structures are created in a biased manner because they are built to serve the advantages of a group of clienteles. Moreover, bias also emerges in structures because of "the relationship between bureaucracy and its democratic sovereigns" (Meier, 2010, p. 286). A top-down or hierarchical structure makes organizations "rigid and static". Thus, democratic organizations will create opportunities for the community to participate and make decisions; people working in the organization can enjoy equal chances to join and help the organization to achieve higher efficiency than totalitarian organizations.

Nevertheless, there is no best way to internationalize public administration. The method of internationalizing public administration varies and depends on the specific context of each university and college where public administration programs are provided. However, undoubtedly, the policy of internationalizing public administration should be advocated because it truly brings more benefits, even though challenges still exist. Foreign students who come to the US to study public administration, or American students who engage in public administration studies in foreign countries will definitely have "increased competitiveness, diversity, global networking, enhanced career and academic choices, better foreign language and intercultural skills, and personal growth and development" (Vest et al., 2014, p. 181). All of these qualifications are necessary for the future public administration arena.

The nature of public administration is an interdisciplinary and multidisciplinary field. Public administration theory borrows from different disciplines, brings different angles, dimensions of problems and interaction collaboration, for example, from the theory of law and political studies, then the theory of economics, sociology, and psychology. Public administration covers various aspects of life from different people to different areas and content because public administration ideas come from different disciplines and it reaches different ends, which results in the disorder in "its models, technique, and methods" (Pollit, 2010, p. 293). The strategy of internationalizing public administration also originates from the nature of public administration field. Thus, the strategy of internationalizing public administration should be adopted and promoted by all countries in the world, from academic to professional areas and from universities to governments. More research needs to be conducted on every issue of public administration, from micro level like the process of production to macro level like the governance issues (Gulick as cited in Meier, 2010). Both foreign and American students of public administration should be provided with knowledge and experiences to engage in the future internationalization process of public administration. 


\section{References}

Altbach, P., \& Teichler, U. (2001). Internationalization and exchanges in a globalized university. Journal of Studies in International Education, 5(1), 5-25.

Barzelay, M., \& Armajani, B. (1992). Breaking through bureaucracy: A new vision for managing in government. California: University of California Press.

Brooks, S., \& Wohlforth, W. (2005). International relations theory and the case against unilateralism. Perspectives on Politics, $3(3), 509-524$.

Carr, E. (1964). The twenty years' crisis, 1919-1939: An introduction to the study of international relations. New York: Harper \& Row.

Corbett, J. (2009). Internationalizing public administration: Acting globally, thinking locally. Proceedings from the 2009 Annual Meeting of the Pacific Northwest Political Science Association. October, Victoria, British Columbia, Canada.

Davies, J. (1998). Issues in the development of universities' strategies for internationalization. Millenium, 3(11), 68-80.

Downs, A. (1967). Inside bureaucracy. Boston, MA: Little, Brown.

Farazmand, A. (1999). Globalization and public administration. Public Administration Review, 59(6), 509-522.

Farazmand, A. (2002). Modern organizations: Theory and practice. Westport, CT: Praeger.

Keohane, R. (1984). After hegemony: Cooperation and discord in the world political economy. Princeton, NJ: Princeton University Press.

Kettl, D. (2000). The global public management revolution: A report on the transformation of governance. Washington, D.C.: Brookings Institution.

Kingsley, D. (1944). Representative bureaucracy: An interpretation of the British civil service. Yellow Springs, OH: The Antioch Press.

Krislov, S. (1974). Representative bureaucracy. Englewood Cliffs, NJ: Prentice-Hall.

Machiavelli, N. (2003). The prince. Wellesley, MA: Dante University Press.

Meier, K. (2010). Governance, structure, and democracy: Luther Gulick and the future of public administration. Public Administration Review, 70(S1), 284-291.

Newland, C. (1997). Realism and public administration. Public Administration Review, 57(2), II.

O’Leary, R., \& Van Slyke, D. (2010). Introduction to the symposium on the future of public administration in 2010. Public Administration Review, 70(S1), 5-11.

Pollitt, C. (2010). Envisioning public administration as a scholarly field in 2020. Public Administration Review, 70(S1), $292-294$.

Poundstone, W. (1992). Prisoner's dilemma. New York: Doubleday.

Shafritz, J., Hyde, A., \& Parkes, S. (Eds.). (2004). Classics of public administration. Belmont, CA: Wadsworth/Thomson Learning.

Steger, M. (2002). The roots of globalism. In M. Steger (Ed.), Globalism: The new market ideology (pp. 1-15). New York, Rowman \& Littlefield Publishers, Inc.

Thucydides. (2006). The history of the Peloponnesian War. New York, NY: Barnes \& Noble Classics.

Van Buuren, A. (2009). Knowledge for governance, governance of knowledge: Inclusive knowledge management in collaborative governance processes. International Public Management Journal, 12(2), 208-235.

Vereshchagin, V. (1889). Realism. Philadelphia, PA: The Pennsylvania Academy of the Fine Arts.

Vest, D., Boyer, L., \& Moses, C. (2014). Internationalizing U.S. colleges and universities while decreasing the trade deficit: The positive double whammy. International Journal of Education Research (IJER), 9(1), 177-185.

Viotti, P., \& Kauppi, M. (1987). International relations theory: Realism, pluralism, globalism. New York: Macmillan.

Waldo, D. (1948). The administrative state: A study of the political theory of American public administration. New York, Ronald Press Co.

Weber, M. (1947). The theory of social and economic organization. New York: Oxford University Press. 